\title{
Entrevista a Fabián Salvioli
}

\section{Justicia transicional: lidiar con el pasado, una cosa del presente para construir el futuro}

\author{
Realizada por videoconferencia el 9/10/2020
}

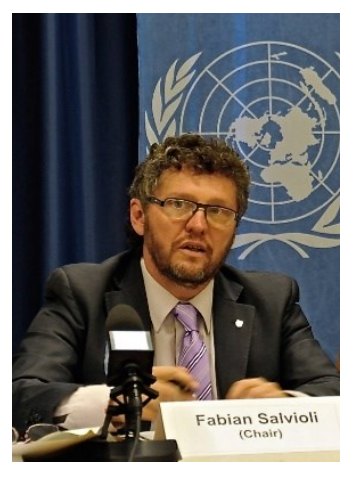

Fabián Salvioli es un jurista argentino, abogado y doctor en ciencias jurídicas por la Universidad Nacional de La Plata; en la Facultad de Ciencias Jurídicas y Sociales de dicha universidad fue profesor titular (catedrático) de la cátedra de Derecho Internacional Público durante veinte años. Actualmente, es titular de la cátedra de Derechos Humanos, dirige el Instituto de Derechos Humanos, y es fundador y director de la Maestría en Derechos Humanos; posee más de ciento cincuenta publicaciones, entre ellas seis libros y artículos científicos sobre derecho internacional, derechos humanos y educación; ha dictado cursos de posgrado, de doctorado y conferencias en más de treinta países de los cinco continentes. Integra las asambleas generales del Instituto Internacional de Derechos Humanos (Estrasburgo, Francia) y del Instituto Interamericano de Derechos Humanos (San José de Costa Rica); co dirige Berg Institute de Relaciones Internacionales (Madrid).

Posee una experiencia práctica de tres décadas en el derecho internacional de los derechos humanos; en el sistema interamericano, litigó y asesoró casos ante la Comisión y la Corte Interamericana, y presidió tribunales ad hoc de reparaciones en el marco de soluciones amistosas; en la Organización de Naciones Unidas integró el Comité de Derechos Humanos entre 2009 y 2016, órgano que también presidió en 2015-2016; asimismo, en el año 2018, el Consejo de Derechos Humanos lo designó Relator Especial de Naciones Unidas para la promoción de la verdad, la justicia, las reparaciones y las garantías de no repetición, cargo que ejerce en la actualidad.

Por su trayectoria ha recibido diversos premios y condecoraciones; entre ellas, fue designado ciudadano ilustre de La Plata, personalidad destacada de la Provincia de Buenos Aires, Graduado Ilustre por la Universidad Nacional de La Plata, profesor honorario en la Universidad de Buenos Aires, profesor honorario en la Universidad Nacional de La Pampa; es miembro honorario de la Academia Mexicana de Derecho, y Doctor Honoris Causa por el Instituto Universitario Puebla, en México.

Esteban Beltrán Verdes Desde junio de 1997 es Director de la Sección Española de Amnistía Internacional, Esta organización de derechos humanos cuenta con más de 92.000 miembros en España, más de 100 grupos de trabajo y es su responsabilidad directa dirigir su Oficina Central en la que trabajan más de 60 personas contratadas y más de 200 voluntarios. Ha sido hasta hace poco Asesor del Secretario General para proyectos globales de Amnistía Internacional en todo el mundo. En la actualidad forma parte del Equipo Global de Gestión de Amnistía Internacional.

Es Diplomado en Estudios de Desarrollo por el Birbeck College de la Universidad de Londres, estudios que realizó del año 1993 al 1995. Es profesor universitario invitado, además, en los Master de Derechos Humanos y Cooperación de las Universidades de Granada y del País Vasco, profesor de investigación de violación de derechos humanos en el Master de Relaciones Internacionales de la Universidad Autónoma de Madrid y profesor del Instituto de Derechos Humanos en el Master de Derechos Humanos de la Universidad Nacional de La Plata. Es autor de varios libros y publicaciones sobre derechos humanos, el más reciente "Derechos Torcidos; Tópicos, mentiras y medias verdades sobre pobreza, política y derechos humanos" (Editorial Debate).

Cómo citar este artículo: Beltrán, E. (2020). Entrevista a Fabián Salvioli. La justicia internacional: el poder de la gente en todo el mundo. Revista Electrónica de Derecho Internacional Contemporáneo, 3 (3), 112 - 120. https://doi.org/10.24215/2618303Xe006 
Esteban Beltrán: - Verdad, justicia y reparación. ¿Es realista pensar que los tres puntos o los tres objetivos deben impulsarse por los gobiernos de forma simultánea? ¿Tienen los tres el mismo valor en tu opinión?

Fabián Salvioli: - Los tres forman parte de una misma cuestión: el cumplimiento de los estándares en materia de Derechos Humanos, yo agrego lo relativo a las garantías de no repetición y el componente de memoria, que creo que es el quinto pilar de la justicia transicional y así lo hice saber en mi último informe al Consejo de Derechos Humanos. Las experiencias muestran que cuando uno de estos componentes falla, el proceso no es exitoso y los problemas subsisten. Dos ejemplos claros, antagónicos: el de España, donde no hubo avances prácticamente y donde tenemos décadas de reclamos y la cuestión encima de la mesa y sin resolver; o el de la ex Yugoslavia, en donde se hicieron fuertes esfuerzos en accountability, porque ha habido sentencias y juzgamientos, un tribunal internacional, cortes nacionales y, sin embargo, el déficit en el componente de memoria nos lleva a la situación de que hoy algunas de las personas que fueron condenadas por crímenes contra la humanidad, terminan sus condenas y son considerados héroes por parte de la población, lo cual es muy, muy serio. Los Estados no tienen la posibilidad de elegir entre estos cinco bloques de los procesos de justicia transicional, son todos componentes que deben cumplir, es como una fórmula química en la cual no puede fallar ningún elemento.

Esteban Beltrán: - ¿Hay algún ejemplo en que los tres se puedan impulsar simultáneamente? ¿Es realista pensar en la misma intensidad de verdad, la misma intensidad de justicia, reparación o garantías de no reparación y de memoria? ¿Es realista pensar que se pueden impulsar simultáneamente?

Fabián Salvioli: - Depende de las circunstancias por las que atraviesen los Estados, el proceso de justicia transicional nunca es rápido. No se pueden solucionar problemas que han tenido décadas de desarrollo en dos meses, o en cuatro o en cinco. Lo que no es realista es pensar que se puede pasar la página en cinco meses de atrocidades que se cometieron durante años. Tomando esto como política de estado y a largo plazo es realista pensar que es factible, luego se va avanzando en medida de lo posible. Nunca hay que resignar la posibilidad de avanzar porque son obligaciones a cumplir por los Estados.

Esteban Beltrán: - Cuándo estabas hablando de justicia transicional ¿por qué poner adjetivos a la justicia? ¿No es un poco el concepto de justicia transicional una especie de justicia light? ¿Por qué hay que agregar transicional a la justicia? ¿No será justicia de lo que hay que hablar?

Fabián Salvioli: - Por supuesto, estoy plenamente de acuerdo y fue el término que se utilizó y se utilizó mal, lo que está en transición no es la justicia, lo que está en transición es el país. Es justicia a la transición por la que vive el país, pero justicia. Los intereses políticos han intentado a lo largo de los tiempos utilizar esta terminología a los efectos de establecer mecanismos que de justicia tienen poco. Es un poco paradójico, yo ahora soy el Relator de Justicia Transicional de Naciones Unidas, pero cuando comencé mi trabajo en Derechos Humanos lo último que quería escuchar hablar era de la justicia transicional porque la justicia transicional era a la justicia, lo que la música militar es a la música. Pero bueno, 25 años después soy el Relator de justicia transicional, aunque yo no cambie, lo que cambió es la justicia transicional.

Esteban Beltrán: - Y hablando de buenos ejemplos ¿Hay algún ejemplo, llamémosle transicional, para no quitarle el apellido a tu relatoría, hay algún modelo de justicia transicional, sea en América 
Latina o en otra región, que te parezca especialmente interesante para destacar en el sentido positivo y cuál es esa cuestión que lo hace en tu opinión destacable? Si es que hay alguno que te parezca destacable.

Fabián Salvioli: - Yo creo que en materia de rendición de cuentas y de accountability el ejemplo en América Latina que mejor funciona es el de Argentina, que cumple bastante con los estándares establecidos hoy por el Derecho internacional penal contemporáneo. En relación a que ciertos crímenes no pueden quedar en la impunidad en ningún caso, con sus dificultades porque las causas de crímenes de lesa humanidad a veces avanzan más, a veces avanzan menos, siempre hay circunstancias centrífugas internas que hacen que la cosa pueda ir un poco más despacio, pero bueno, avanza. Los ejemplos de las comisiones de la verdad en Perú y en Brasil, han sido muy buenos, son dos comisiones de la verdad que han funcionado efectivamente muy bien. La comisión de la verdad de Perú ha tenido, por ejemplo, un valioso enfoque de género; es una de las primeras comisiones de la verdad que ha tenido un enfoque de género y eso es algo realmente destacable. Y por ejemplo Chile, que tiene un serio déficit de accountability, de todas maneras ha establecido muy buenos programas nacionales de reparación en lo que tiene que ver con rehabilitación médica, psicológica y psiquiátrica. Todos sabemos que este tipo de crímenes dejan secuelas muy fuertes a nivel físico, psíquico y psiquiátrico. En otros lados, a pesar de los esfuerzos hechos por la comunidad internacional, que han sido muchos y grandes tanto de órganos oficiales como Naciones Unidas o de organizaciones no gubernamentales como Amnistía Internacional, por ejemplo, Guatemala ha sido caracterizado por la falta de voluntad política de avanzar en la dirección en la que hay que avanzar. El Salvador es un ejemplo doloroso, más de treinta años después se constatan aún muchos déficit, lo he podido comprobar en mi último viaje al país, lo que se refleja en el informe oficial que presenté hace unos días al Consejo de Derechos Humanos.

Esteban Beltrán: - Dos preguntas concretas. Primero en relación al concepto de rendición de cuentas: para que realmente la accountability tenga sentido y aquellos que cometieron crímenes de Derecho internacional comparezcan ante los tribunales, entiendo que es clave que se acometa inmediatamente la investigación según terminen la dictadura o termine el conflicto armado, la rendición de cuentas pierde su sentido si se tarda mucho tiempo entre los hechos acaecidos y la investigación ¿porque cómo puede ser esa rendición de cuentas cuando pasan mucho tiempo? Y lo mismo en garantías de no repetición, por ejemplo, lo que mencionabas de El Salvador. En El Salvador quizás en los informes de verdad no se mencionara los responsables directos ipudo influir en que ahora sean están repitiendo alguno de los errores de han sucedido en el pasado?

Fabián Salvioli: - A la primera de las preguntas, sí por supuesto, coincido plenamente en que el proceso de accountability tiene que ser lo antes posible, y se debe llevar adelante porque a medida que el tiempo pasa es más compleja la producción de prueba, y además de que es más compleja la prueba se genera una fuerte sensación de frustración en las víctimas. En general se observa que en algunas comunidades las víctimas terminan conviviendo con sus perpetradores a pocos metros, lo cual es escalofriante y a mi juicio revictimizante. Entonces un proceso de justicia transicional en esas condiciones, tiene cualquier cosa menos justicia. Ahora, cuando no ha habido posibilidades de hacerlo antes porque los Estados han establecido leyes de impunidad, etcétera, trabas de distinto tipo, bueno, más vale tarde que nunca, la justicia debe ser perseguida, aunque hayan pasado muchas décadas.

En relación a la segunda pregunta, mi respuesta es: no lo sé. No estoy tan seguro de que las cuestiones de repetición de hechos tengan que ver con una causa-efecto con lo que vos mencionabas directamente. Si me parece fundamental el restablecimiento de la confianza de la sociedad en el Estado. Hay un término que se 
utiliza muy perversamente en la justicia transicional que "reconciliación" pretendiendo que las víctimas se reconcilien con los verdugos, lo cual es una barbaridad, es una absoluta barbaridad. La reconciliación se tiene que dar entre las víctimas y el Estado, es decir las víctimas que perdieron la confianza en el Estado, que en lugar de ser una máquina de garantizar derechos, que es lo que debe ser porque esa es la función del Estado, se convirtió en una máquina de matar; esas víctimas han perdido la confianza en el Estado y necesitan reconciliarse con él. La reconciliación sí sucede después de que el Estado tomó todas las medidas de garantía de no repetición, reformas institucionales y lo que se conoce como el proceso de vetting, pero con el Estado, no con los perpetradores que deben ser juzgados y condenados. En conflictos entre grupos o guerras internas, igualmente la reconciliación se da entre las facciones, no con las personas que dentro de las facciones han cometido crímenes que el derecho internacional no acepta e impone condenar.

Esteban Beltrán: - Vamos a pasar otro concepto de la parte de rendir cuentas a la parte de la comisión de la verdad. La comisión de la verdad ¿Cómo se compara con un proceso judicial que busque a los responsables, cuál es esa tensión que ha habido en algunos lugares, entre una comisión verdad que busca la verdad absoluta pero que no nombra a los responsables? O como en Sudáfrica pues si eras responsable y si lo declarabas responsables te librabas, ¿cómo se compara respecto a los procesos judiciales que hace investigaciones penales y busca responsabilidades penales? ¿Hay alguna tensión? ¿Hay algo que veas que pueda ayudar a que no exista esa tensión?

Fabián Salvioli: - Es un gran planteo que obedece a que en los inicios de los procesos de justicia transicional se ha planteado una falsa dicotomía entre verdad y justicia, y para mí son absoluta y necesariamente complementarias, no contradictorias. La comisión por la verdad tiene objetivos diferentes, es una verdad general, es una verdad que no abarca a todos y cada uno de los casos, es una verdad que documenta un determinado proceso histórico para que la sociedad lo conozca y es una verdad que puede servir como elementos de prueba a los efectos de los procesos judiciales, de ninguna manera sustituirlos. Son mecanismos completamente distintos y los dos son imprescindibles. Sin verdad no hay justicia, pero sin justicia no se cumplen las expectativas de las víctimas y en ese sentido entonces podemos decir que no es factible la paz. La justicia sin la paz de las víctimas no es justicia. Sino ¿de qué tipo de paz estamos hablando?

Esteban Beltrán: - ¿En tu opinión pueden convivir lo que es la verdad judicial con la verdad administrativa o del Estado en reconocer lo que ocurrió? ¿Hay tensión o deberían coincidir?

Fabián Salvioli: - Deben, deben convivir por supuesto; hay que entender que el proceso judicial tiene otras cosas que son importantes como las garantías a respetar para las personas imputadas. $\mathrm{O}$ sea, el hecho de que una persona no haya podido ser encontrada culpable de la comisión de un genocidio, no quita el hecho de que se haya cometido un genocidio, entonces, son dos cosas que deben ir conjuntamente. Como señalaba: verdad, justicia, reparación, garantías de no repetición y memoria, son cinco elementos indispensables, no pueden faltar componente de ninguno en un proceso de justicia transicional. En torno a las comisiones de la verdad y también el resto, es muy importante que las víctimas no sean actores pasivos. Las víctimas deben participar en el proceso de justicia transicional desde el inicio y no como convidadas de piedra para legitimar procesos que diseñan otros. Desde el diseño a la implementación, la voz de las víctimas no sólo tiene que estar, debe ser prioritaria y debe ser atendida, eso es imprescindible. Los procesos de justicia transicional que se llevan a cabo en nombre de víctimas, sin que las mismas hayan tenido la posibilidad de participar ampliamente y decidir qué cosa sí y qué cosas no, no son válidos. 
Esteban Beltrán: - Te quería preguntar por algo que ha quedado como una situación de limbo de verdad, justicia y reparación: el caso de Colombia. Limbo en el que no se sabe muy bien cómo está la situación, sí hay proceso de paz, si se termina el proceso de paz o si sigue el proceso de paz. En tu opinión, ¿cuál es la situación en Colombia desde el punto de vista de la verdad, justicia y reparación en un conflicto armado de 50 años? ¿Cuáles serían tus valoraciones en la situación de Colombia?

Fabián Salvioli: - Puedo hacer valoraciones muy preliminares porque naturalmente es un país que estoy estudiando, estoy examinando y de ninguna manera puedo adelantar conclusiones. Colombia es el laboratorio de justicia transicional que hay en el mundo. Yo he pedido visita oficial al Estado, el Estado me la ha negado, lo cual es bastante paradójico que el Estado que tiene el mecanismo de justicia transicional sobre el que están los ojos del mundo no acepte la visita oficial del Relator sobre justicia transicional; eso quiere decir algo naturalmente, imagino que el Estado va a revertir esta posición, espero, en breve. Yo creo que se han hecho esfuerzos importantes, y que los acuerdos de paz fueron un buen esfuerzo. El problema es, que la realidad que estamos viviendo no se compadece, y esto no significa violar ninguna regla de mi mandato, basta con ver los informes y las preocupaciones de otras relatorías de Naciones Unidas sobre ejecuciones extrajudiciales de líderes campesinos y otros problemas muy serios; pareciera que hay sectores que claramente se resisten a entender y a aceptar que el conflicto armado ha finalizado. Es evidente, hoy tenemos un número elevado de ejecuciones extrajudiciales y de actos en contra determinados grupos y personas. La comisión de la verdad de Colombia está haciendo un gran trabajo. Incluye, por ejemplo, como otro factor valioso $\mathrm{y}$, esto podemos lo hilar con la primera pregunta sobre las comisiones de verdad, la situación que atraviesan los colombianos en la diáspora -que se encuentran en otros países-; en ese sentido, funciona muy bien.

Luego, a nivel de reforma institucional el Estado ha tomado medidas también que me parecen importantes y valiosas. Hay un gran tema que quedó abierto en el proceso de paz, y ese será un serio problema, que es cómo implementar las cuestiones relativas a las restituciones de tierras. Colombia es uno de los países en los que mayor desplazamiento forzado ha habido, en buena medida de poblaciones indígenas, dejando lugares que han terminado siendo usurpados por paramilitares, y que no quieren devolverlos, y eso ha quedado en una nebulosa en relación a la implementación, es un punto álgido y creo que va a traer muchos problemas. Y luego, el accountability es sobre lo que no debo expedirme claramente, porque está en funcionamiento la justicia especial de paz, y a mí me interesa ver los resultados para poder compararlos con los estándares internacionales a los efectos de decir si es compatible o no con las obligaciones de los Estados en materia de derechos humanos.

Esteban Beltrán: - La parte de Colombia que parece muy relevante que mencionas del conflicto de tierras es efectivamente una de las razones del conflicto armado en ese país y efectivamente toda la estructura que se creó dentro de Colombia para solventar el regreso de gente sin temor a tierras que prácticamente no se ha cumplido en un 90\%. Entonces toda esa conquista de paramilitares, y de las mejores tierras, donde la gente se quedó desplazada, pues es una asignatura pendiente muy seria y todo el programa de restitución de tierras de los antiguos gobiernos colombianos, también en mi opinión no ha logrado el efecto de reparación, de reconocimiento y garantías de no repetición.

Un aspecto que quería también que analizaras Fabián, es la relación entre procesos de justicia transicional, entre la justicia de un país, la justicia de otros paises y la justicia del Tribunal Penal Internacional y su impacto. Y también la justicia universal, ese concepto extraordinario de justicia que frente a afrentas contra todos nosotros o nosotras que cualquier juez debe investigar en cualquier lugar del mundo ¿Cómo eso se comparece en un tema de justicia transicional o la investigación que hacen los propios tribunales o la falta 
de investigación que hacen los propios tribunales en un país o cuándo, eventualmente, debe actuar el Tribunal Penal Internacional? Es decir, esa combinación, para garantizar la justicia y la rendición de cuentas, ¿cuándo debe ser nacional y cuándo debe ser internacional? Esa tensión, me gustaría que la analizaras brevemente.

Fabián Salvioli: - Es un tema extraordinario, a mí me ha tocado trabajarlo muy de cerca. Hay que comprender que el sistema internacional siempre debe ser visto de manera complementaria, siempre es complementario y que el peso más fuerte, el peso en realidad recae fundamentalmente sobre los Estados nacionales. Entonces, el Estado nacional no puede decir que tiene dificultades para juzgar e iniciar las acciones pertinentes utilizando como excusa que a nivel internacional se juzga muy poco, porque el plano internacional es para "juzgar muy poco". El plano internacional no se puede colapsar con todos los casos de todos los países, es imposible que un tribunal internacional absorba todo eso, explota. El espacio efectivo de la justicia es el campo nacional. El campo nacional debe llevar a cabo la justicia conforme a los estándares y los estándares son que los más graves crímenes no pueden quedar impunes y deben ser perseguidos. Deben ser perseguidos por el sistema penal. Si el lugar de la comisión de los hechos, es decir allí donde rige la territorialidad, donde se han cometido efectivamente los hechos, no funciona, el Estatuto de Roma tiene una previsión extraordinaria en el preámbulo que dice que: es deber de todo Estado Parte, juzgar a los responsables de los más graves crímenes; no dice a los responsables de los más graves crímenes cometidos en su territorio. A mi juicio, el preámbulo del Estatuto de Roma establece una obligación para los Estados de tipificar la jurisdicción universal, y esa debe ser una campaña de las organizaciones no gubernamentales, señalando que todos los Estados Partes deben establecer jurisdicción universal para complementar aquella jurisdicción territorial que no haya cumplido con los objetivos de condenar estos crímenes. Porque como bien vos decís, toda la humanidad es afectada por esta situación. Y allí, cuando a nivel interno ni por el país, ni por otros países del Estatuto de Roma se puede hacer justicia, es dónde la Corte Penal Internacional tiene, a mi juicio, la obligación de actuar. Cuando digo la obligación de actuar también me quiero referir a una cuestión, quiénes puedes iniciar un asunto ante la Corte Penal Internacional son la Fiscalía de la Corte, un Estado Parte en el Estatuto, o el Consejo de Seguridad de Naciones Unidas. Ahora, se da una situación, a mí me tocó participar en la Conferencia de Roma en ese momento representando al Secretariado internacional de Amnesty, que las ONG planteamos en aquella oportunidad como el "veto del Pol Pot", es decir, qué pasaba sí los crímenes se cometían en un país contra nacionales de ese país y ese país no había ratificado el Estatuto de Roma. Allí, el asunto no podía llegar ni por la vía de la Fiscalía, ni por la vía del Estado Parte, entonces ahí yo creo que, la facultad del Consejo de Seguridad de Naciones Unidas se convierte en obligación. El Consejo de Seguridad de Naciones Unidas tiene la obligación, a mi juicio, de mandar el asunto a la Corte para cumplir con el objetivo del Tratado de Roma y, el objetivo del Tratado de Roma, es que los crímenes más atroces no queden impunes. El Consejo de Seguridad no debería tomar esa atribución que tiene como una facultad, sino como una obligación de actuar cuando no se dan las circunstancias establecidas para el ejercicio de la competencia de la Corte.

Esteban Beltrán: - Es interesante, porque más o menos, se estima que un 70 u 80 \% que tienen en sus legislaciones los países, la posibilidad de actuar en materia de justicia universal, sin embargo, se cuentan con los dedos de una mano los paises que toman acciones en ese sentido. Pareciera que existe la posibilidad de la justicia universal en muchos países del mundo, pero no se hace en la práctica. Es excepcional lo que Alemania está haciendo ahora con algunos casos de Siria, o Francia en el pasado incluso con algunos casos de Argentina, etc. ¿Llegará un momento que la legislación se convertirá en práctica en tu opinión? Porque ya es un avance importante que esté la legislación, pero no existe esa práctica. 
Fabián Salvioli: - Sí, yo creo que tampoco hay que ser naif, hay que entender que detrás de ese tipo de causas casi siempre hay muchos movimientos políticos turbulentos dentro de los Estados. A ningún Estado le gusta etener problemas con otro. Entonces cuando quienes administran justicia en un Estado, llaman a personas relevantes de otro Estado a rendir cuentas, casi siempre hay una pequeña electricidad diplomática, y eso se amplía mucho más cuando el Estado en cuestión es un Estado poderoso o un Estado que tiene un interés económico muy grande o muy alto, allí es muy difícil que la propia justicia se anime a avanzar en esa dirección. El ejemplo de España ha sido claro, la justicia universal ha funcionado de maravillas con el caso argentino, ha funcionado de maravillas con el caso guatemalteco y cuando se quiso avanzar en un asunto relativo a un caso chino, se reformó la ley de justicia universal, porque eso le generaba un serio problema diplomático a España con China, que sabe presionar muy bien, digamos, que sabe hacer su trabajo muy bien. De todas maneras, este camino siempre ha sido difícil, siempre ha sido lento, el de la accountability, pero se han dado progresos extraordinarios. Quienes trabajábamos en Derecho Humanos hace 25 o 30 años, allí cuando vos y yo nos conocimos, quizás pensábamos esto como una cosa inviable, absolutamente inviable, y hoy al menos estamos discutiendo sobre si hay dificultades para la implementación o no. Lo cual muestra que el camino de la militancia y el trabajo en Derechos Humanos vale la pena.

Esteban Beltrán: - Absolutamente, yo creo que cuando tú y yo nos conocimos el Derecho internacional era fundamentalmente una materia de la Universidad (risas) y hoy es en la práctica un elemento de Justicia, entonces, es un cambio sustancial. Dos últimas preguntas, Fabián. Una tiene que ver las amnistías, ¿hay alguna amnistía que se pueda aceptar por crimenes de Derecho internacional? ¿Por alguna razón?

Fabián Salvioli: - La única amnistía que se puede aceptar es Amnistía Internacional que es una ONG maravillosa que trabaja por los Derechos Humanos en todo el mundo y que nació para liberar a los presos de conciencia que estaban encarcelados por sus opiniones. No son factibles ni amnistías, ni mecanismos de impunidad, indultos, o perdones para crímenes contra la humanidad o para crímenes de guerra, los efectos de esas leyes son nulos. Ya hay suficiente establecimiento jurisprudencial sobre ello: la Corte Interamericana de Derechos Humanos lo ha dejado sentado desde el caso Barrios Altos en adelante. Las amnistías han caído por su propio peso, lo único que genera una amnistía es diferir el problema para más adelante, los Estados no deben recurrir en esos mecanismos. Esto ya ha sido consagrado a nivel mundial en el propio Estatuto de Roma. A mí me pasa mucho cuando entrevisto a Estados de distintos lugares del mundo en el ejercicio de la Relatoría que te dicen: sí, sí iniciamos un proceso de justicia transicional vamos a hacer esto, esto otro y vamos a establecer una amnistía, como si quisieran negarse a entender que ya hace 25 años que eso no es aceptable, que se podía pensar en eso a inicios de los ' 80 , pero eso ya no es aceptable. La comunidad internacional ha tomado otra decisión, y es que esos hechos lo único que generan es que nunca se pueda terminar de dar vuelta a la página y, otra vez el ejemplo de España, es evidente, allí están las víctimas pidiendo justicia, con toda razón y cuando las víctimas se mueran, quienes pedirán justicia serán sus hijos y cuando se mueran sus hijos, serán sus nietos, pero algún día esa justicia va a llegar. Un Estado sano, democrático, valiente, lo que debe hacer es abordar esa cuestión como corresponde, hacer justicia de una buena vez a las víctimas, no re victimizarlas y entonces sí avanzar en una sociedad efectivamente integrada en una cultura de paz.

Esteban Beltrán: - Última pregunta sobre España, has mencionado varias veces a España. En mi país en 85 años, primero por una dictadura y, luego pues la democracia, prácticamente no ha habido verdad y justicia ni reparación oficial, a ninguna víctima, por todo lo que se sufrió durante la guerra civil y la dictadura. Sin embargo, es una reivindicación que continúa por una parte de la 
sociedad, no mayoritaria. Ahora hay pasos que se están dando para la posibilidad de que haya un tipo de avances en ese sentido, pero todavía un poco indefinidos ¿Cuál es en tu opinión lo que deberian hacer primero las autoridades españolas para avanzar en verdad, justicia y reparación? ¿Cuál sería la secuencia más correcta para avanzar en verdad, justicia y reparación en tu opinión en España?

Fabián Salvioli: - Es una pregunta muy difícil por qué me haces elegir entre cosas que son imprescindibles, pero en término de elegir, hay una cuestión que a mí me parece de un tremendo dolor y que ya no debe ser aceptable. Que el esfuerzo por localizar y sacar a las víctimas de ejecuciones extrajudiciales de fosas comunes, ha quedado en manos de las propias víctimas. Esto es realmente escandaloso, es realmente escandaloso que el Estado no se ponga al frente de esa actividad. Es escandaloso tener que aclarar que una cuneta no es un cementerio y que hay personas de una edad muy avanzada que lo único que quieren es recuperar los huesos de sus familiares para poder darles una sepultura conforme a sus creencias y hacer el duelo. ¿Quién puede oponerse a eso? ¿¿Quién?! Ya no estamos hablando de juzgar a tal persona, estamos hablando de darle los huesos de su padre a una persona que ya está por morir y que te dice, cómo me han dicho personas que yo he entrevistado, quiero hacer esto para morirme en paz. Por supuesto que hay que hacer todo, pero en términos de urgencia eso me parece que no hay que hacerlo hoy, hay que hacerlo ayer. Ahora, el Estado no debería, si se encarga de eso, decir: - "No, no fíjense que estamos haciendo esto". Tiene que hacer todo lo otro también, y mucho más un Estado con recursos, desarrollado, que tiene todos los elementos para llevar adelante esta cuestión. Y debe ser una política de Estado. Debe ser una política de Estado, independientemente de los gobiernos. Yo sé que esto es difícil que es realmente difícil. Recuerdo cuando presidí el Comité de Derechos Humanos de Naciones Unidas y nos tocó examinar a España y yo quedé francamente alucinado de la respuesta de la Jefa de delegación y su comitiva; en un momento, uno de los responsables de la cartera de Justicia del Estado, diciendo públicamente: "nosotros hemos decidido la amnesia". La amnesia no se decide, ¿la amnesia de quién? No se decide la amnesia, de nadie se decide la amnesia. Cuando conversas con las víctimas hoy, el dolor es actual, es actual y me atrevería a decir que el dolor es mayor. Porque en ese tipo de situaciones el paso del tiempo genera más dolor. Entonces, esa es una medida, pero ya se han perdido 80 años, así que no hay excusas, hay que poner todos los elementos del Estado, para hacer lo que hay que hacer y, si no, nunca se va pasar la página. Lo que hoy sucede todavía, por ejemplo, con Armenia: ahí están reclamando en relación al genocidio de armenios que pasó hace un siglo y así será por generaciones. La paz no se impone, la paz se construye y la paz construye con memoria, verdad, justicia, reparaciones, garantías de no repetición y cultura de paz.

Esteban Beltrán:- Ahora sí, la última pregunta Fabián, saliendo de esta reflexión me ayuda pensar que mucha gente piensa que verdad, justicia y reparación tiene que ver con lidiar con el pasado, con lo que ocurrió en tu pais, en tu región, pero tiene un importante componente de futuro, que tú has apuntado. Me gustaría que como parte final de esta conversación apuntaras cuáles son las partes del futuro que ganamos tratando con el pasado, tratando bien al pasado. ¿Cuál es la parte de futuro que ganamos?

Fabián Salvioli: - Mucha, muchísima. A eso le dediqué mi último informe en el Consejo de Derechos Humanos. Mi informe fue sobre memoria. Hay una conexión directa entre la impunidad, y la falta de avance en materia de justicia transicional y los procesos de memoria. Todo el déficit en esa materia se refleja en algunos lugares en violaciones contemporáneas de derechos. El ejemplo de El Salvador es evidente: hay elementos muy claros de vínculos de violencia entre hechos del pasado no abordados debidamente y lo que pasa actualmente. Lo mismo sucede en Guatemala. Hay que abordar adecuadamente el pasado porque hay que hacer justicia a las víctimas. A mí me parece absolutamente inaceptable que todo el mundo entienda que 
si una persona te choca el coche tiene la obligación de reparar, y que por otro lado tengamos que estar explicando que, si te han torturado, masacrado, etc., tienen que reparar esos daños. Parece mentira que una sociedad que se ha construido sobre la idea de que quién generó un daño debe reparar, tenga una resistencia tan enorme a que los daños más tremendos sean efectivamente reparados. Hay que hacerlo porque hay que hacerlo, pero además, es un ejemplo para el futuro de esa comunidad. La comunidad le dice a todo el mundo "esto no es aceptable, esto no es tolerable, nosotros nos ponemos del lado de que hay límites, de que un Estado o grupos de oposición, no pueden hacer cualquier cosa en relación a las personas, y entonces cuando eso sucede lo abordamos correctamente. Y lo abordamos correctamente y así construimos una cultura de paz". Eso hace al comportamiento cotidiano en materia de Derechos Humanos. Es lo único que efectivamente que va a llevar a tener un mundo en paz y seguridad, que no se puede decretar por el solo hecho de que el artículo 1 de la Carta de Naciones Unidas lo diga. Eso se construye, no aparece mágicamente y se construye de la base de los Derechos Humanos, que es el concepto más poderoso que el Derecho le ha dado a la humanidad en el siglo XX, y es la herramienta imprescindible para que la paz no sea sólo la ausencia de guerra, sino el marco en el cual cada persona pueda diseñar y llevar adelante sus proyectos de vida.

Esteban Beltrán:- ¡Muchas gracias Fabián! 